\title{
THE EFFECT OF PILATES EXERCISE ON ANXIETY IN STUDENTS OF DEPARTMENT OF MEDICAL EMERGENCY- A CLINICAL TRIAL
}

Mahnaz Abavisani1 ${ }^{1}$ Rasool Lakzian², Zohreh Sarchahi ${ }^{3}$ Samaye Jafariani ${ }^{4}$, Hani Pourjafar 5

\author{
1MSc. of Medical Surgical Nursing, Department of Nursing, Faculty of Nursing, Neyshabur University of Medical Science, Neyshabur, \\ Iran. \\ 2MSc. Student of Critical Care Nursing, Rajaee Cardiovascular Medical and Research Center, Tehran, Iran. \\ 3MSc. of Medical Surgical Nursing, Department of Nursing, Faculty of Nursing, Neyshabur University of Medical Science, Neyshabur, \\ Iran. \\ ${ }^{4}$ Department of Health, Neyshabur University of Medical Science, Neyshabur, Iran. \\ ${ }^{5}$ Student of Medical Emergency, Student Research Committee, Neyshabur University of Medical Science, Neyshabur, Iran.
}

\section{BACKGROUND}

ABSTRACT

Anxiety phenomenon is not new, and humans have experienced it with every culture and in all ages. Based on literature review, Pilates is a time- and cost-effective sport and more enlivening as compared to other methods for alleviating anxiety and is more acceptable to the students. Considering limited number of studies in this regard, the present trial was carried out to explore the effects of Pilates on anxiety in students of department of medical emergency in Neyshabur University of Medical Sciences.

\section{METHODS}

This clinical trial was conducted on 62 students of department of medical emergency. After accessible sampling, the subjects were randomly allocated to the two groups of intervention and control. In the experimental group, Pilates was performed during two 60 minutes sessions per week for 8 weeks with the help of an instructor. The collected data was analysed using descriptive (mean, standard, percent and frequency) and interpretive tests. SPSS Ver.14 used for data analysis. A chi-square test was used for comparison of two groups.

\section{RESULTS}

The mean and SD score of obvious anxiety before the intervention were $52.74 \pm 7.41$ and $52.48 \pm 7.27$ in experimental and control groups, respectively. However, after the intervention, the mean \pm SD score of obvious anxiety were $49.63 \pm 7.39$ and $51.81 \pm 7.16$ in experimental and control groups, respectively.

\section{CONCLUSIONS}

This study showed the positive effect of Pilates on the improvement of anxiety among students of department of medical emergency. Therefore, it is recommended as an appealing technique without side effects to reduce anxiety among university students.

HOW TO CITE THIS ARTICLE: Abavisani M, Lakzian R, Sarchahi Z, et al. The effect of Pilates exercise on anxiety in students of department of medical emergency- a clinical trial. J. Evolution Med. Dent. Sci. 2019;8(21):1755-1758, DOI: $10.14260 /$ jemds/2019/385

\section{BACKGROUND}

One of the main concerns in educational system is students anxiety which is hard to bear for most students.(1,2) Anxiety phenomenon is not new and humans have experienced it with every culture and in all ages.(3) No doubt, university students are key sources for progression in every nation. Students of Department of Medical Emergency with certain issues related to their field including time limitation, patient's critical status, relatives' expectations, Highly charged atmosphere, fear of failure to rescue a dying patient, ability to make decisions in critical settings, experience stresses which make them more susceptible to impaired self-esteem and increased anxiety. ${ }^{(4)}$

'Financial or Other Competing Interest': Dr. Sarchahi reports grants from Neyshabur University of Medical Science, outside the submitted work.

Submission 06-04-2019, Peer Review 14-05-2019,

Acceptance 20-05-2019, Published 27-05-2019.

Corresponding Author:

Zohreh Sarchahi,

MSc. of Medical Surgical Nursing,

Department of Nursing, Faculty of Nursing,

Neyshabur University of Medical Science, Neyshabur, Iran.

E-mail: sarchahiz1@nums.ac.ir

DOI: $10.14260 /$ jemds $/ 2019 / 385$
Anxiety presents in form of a complicated condition from mild to severe which impairs learning and various factors could causes anxiety such as clinical experiences and change in educational environment.(1) About $53.3 \%$ of students in department of medical emergency are at risk of mental damages, stressors vulnerability, poor academic performance, misbehaviour, physical and psychological problems and poor performance on the patients' bedside.(5) Anxiety leads to academic failure and sometimes dropouts.(6) Insufficient physical activity in Mediterranean countries including Iran is estimated to be 30-70\%.(7) Gold Field and colleagues (2012) showed that physical activity is essential for having sense of competency and positive mental image and for confronting stress and anxiety.(8) Reppa (2013) showed that Pilates and Yoga exercises in combination led to increased self-esteem and reduced stress and anxiety.(9) The findings from Mokhtari and colleagues (1390) indicated a $20 \%$ reduction in stress and anxiety and increase in different aspects of life including selfesteem through Pilates training.(10) In recent years, Pilates training has received considerable attention from sport and rehabilitation professionals and is pervasive. Pilates is a physical fitness system developed in 1920 by Joseph Pilates.(11) In this sport, emphasis is on controlled movements, body positioning and breathing.(12) Pilates (Contrology) is 
described as complete coordination between body, and soul.(13)

This training technique consists of controlled movements which create physical harmony between body and brain and increase physical and mental ability at any age. As opposed to other sports with only focusing on physical aspects, Pilates considers physical and mental aspects at the same time and is based on body and Mind coordination which leads to physical and mental health.(14) In health definition, both physical and mental dimensions are considered and health is described as lack of illness and/or lack of any impairments in physical and mental aspects.(15) Joseph Pilates showed that Pilates is based on six general principles including relaxation, concentration, precision, coordination, movement and breathing.(16) This technique is performed in static, supine, sitting and standing modes and without going through any distance and jumping. Therefore, the advantage of this training is that it reduces the risk of muscular and joint damages associated with throwing movements and is practicable in every environment (Home, work place, outdoor and indoor and ....) and all in the society.(17) Based on literature review, it is a time- and costeffective sport and more enlivening as compared to other methods for alleviating anxiety and is more acceptable by the students. Considering limited number of studies in this regard, the present trial was carried out to explore the effect of Pilates on anxiety in students of department of medical emergency in Neyshabur University of Medical Sciences.

\section{METHODS}

This clinical trial was carried out in Neyshabur city in 1396.62 students of department of medical emergency from Neyshabur University of Medical Sciences were selected (The programs in this group focused on disaster ad emergency events contents). The inclusion criteria were as follows: no previous or current history of physical and mental illness (Cardiovascular and respiratory disorders, diabetes, renal disease, musculoskeletal disorders such as scoliosis and other disorders with physical activity restraint), age group of 19-40 years, no regular physical activity in last month, students of department of medical emergency, no incidence of stressful events in past 6 weeks including marriage and divorce (The individual or their parents), onset of severe disease in study subjects or their family members, death of friends or relatives, less than 2 hours sport activity per week. Unwillingness to participate and membership of sport teams were considered as exclusion criteria. Sample size was considered as 28 in each group based on mean difference and $95 \%$ confidence interval. Considering $10 \%$ attrition probability, 31 subjects in each group and total of 62 were determined as study sample size. After nonprobability convenience sampling, subjects were allocated into intervention and control groups using block randomization method. Blocks with size of 4 were created and subjects within each block were randomly divided into two groups, A and B. After assignment of ethical code and obtaining necessary permissions, the main author received a full list of students of department of medical emergency, based on an organized framework and related semester. Study objectives were explained to the eligible participants and informed consent was obtained. Data collection was carried out using a demographic questionnaire and Spielberger obvious and hidden anxiety inventory. Obvious and hidden anxiety inventory consists of separate self-assessment scales for measuring obvious and hidden anxiety. Obvious anxiety scale included 20 statements which evaluate the individual feelings in the moment and at the time of answering. Hidden anxiety scale consisted of 20 statements which measure usual and general feelings of individuals. A digital Seca scale was used for recording weights and a graded plastic meter was applied for height measurements in order to calculate body mass index for each subject. Weight was recorded with clothing without shoes between 8 to $10 \mathrm{AM}$ to the nearest $100 \mathrm{~g}$. Height was estimated using an upstretched tape without shoes and was registered to the nearest $1 \mathrm{~cm}$. All measurements were carried out by one person and Body mass index (BMI) was calculated as weight in $\mathrm{kg}$ divided by height in $\mathrm{m}^{2}$. In the intervention group, anxiety was examined before and immediately after the intervention using Spielberger obvious and hidden anxiety inventory. Pilates were performed during two 60-Minutes sessions for 8 weeks with the help of an instructor. After 11 Minutes of warm up, Pilates' preparation techniques including standing, breathing, reaching the floor by two hands and level 1 movements including the hundred, pilates curl, single leg stretch, double leg stretch, single leg curl, rolling like a ball and Stretching the Spine forward were performed. Control group continued their regular activities during study time without any intervention. After this time, both groups completed Spielberger anxiety questionnaire. Subject in the control group completed the questionnaire before after the study period. Data analysis was conducted using descriptive analysis, independent and paired $\mathrm{T}$ tests and multivariate covariance analysis. The study was approved by the Research and Ethics Committee of Neyshabur University of Medical Sciences (IR.NUMS.REC.1396.35) and registered in in Iranian Registry of Clinical Trials (IRCT20181118041692N1). Ethical considerations such as informed consent, confidentiality of information, the right to discontinue in any time during study period and moral rights of creators in print and electronic sources were observed.

\section{Statistical Analysis}

The collected data were analysed using descriptive (Mean, Standard, Percent and Frequency) and interpretive tests. SPSS Ver.14 used for data analysis. A chi-square test was used for comparison of two groups.

\section{RESULTS}

In this study, 62 eligible students were recruited. 31 subjects were assigned to each study groups (Intervention and control). There was no dropouts and final analysis was performed on all 62 initially selected subjects. The mean age in both groups was $23.77 \pm 2.69$. $25 \%$ and $22 \%$ of study subjects in the intervention and control groups were single. There was no significant difference between the two groups in terms of demographic variables including marital status, age and accommodation type (Table 1).

The mean (SD) score of obvious anxiety before and after the intervention was $52.74 \pm 7.41$ and $49.63 \pm 7.39$ in the experimental group and the difference was statistically significant ( $\mathrm{p}=0.001)$. In the control group, the mean (SD) of obvious anxiety before the intervention was $52.48 \pm 7.27$ which was reduced to $51.81 \pm 7.16$ afterwards. However, the difference was not statistically significant ( $p=0.13$ ) (Table 2). 


\begin{tabular}{|c|c|c|c|c|c|}
\hline Variable & & $\begin{array}{c}\text { Intervention } \\
\text { Group } \\
\text { Number } \\
\text { (Percent) } \\
\end{array}$ & $\begin{array}{c}\text { Control Group } \\
\text { Number } \\
\text { (Percent) }\end{array}$ & $\begin{array}{c}\text { Total } \\
\text { Number } \\
\text { (Percent) }\end{array}$ & $\begin{array}{c}\text { p } \\
\text { Value }\end{array}$ \\
\hline \multirow{2}{*}{$\begin{array}{l}\text { Marital } \\
\text { status }\end{array}$} & single & $25(80 / 6)$ & $22(71)$ & $47(75 / 8)$ & \multirow{2}{*}{0.38} \\
\hline & Married & $6(19 / 4)$ & $9(29)$ & $15(24 / 2)$ & \\
\hline \multirow[b]{2}{*}{$\begin{array}{c}\text { Residence } \\
\text { type }\end{array}$} & Native & $19(61 / 3)$ & $23(74 / 2)$ & $42(67 / 7)$ & \multirow[t]{2}{*}{0.28} \\
\hline & Non-native & $12(38 / 7)$ & $8(25 / 8)$ & $20(32 / 3)$ & \\
\hline \multirow{3}{*}{ Semester } & First & & $12(38 / 7)$ & & \multirow{3}{*}{0.08} \\
\hline & Middle & & & & \\
\hline & Last & $5(16 / 1)$ & $11(35 / 5)$ & $16(25 / 8)$ & \\
\hline \multirow{4}{*}{ Age } & -21 & & & & \multirow{4}{*}{0.39} \\
\hline & & $16(51 / 6)$ & & & \\
\hline & $25-27$ & $6(19 / 4)$ & $8(25 / 8)$ & $14(22 / 6)$ & \\
\hline & $28-30$ & $2(6 / 5)$ & $5(16 / 1)$ & $7(11 / 3)$ & \\
\hline \multirow{4}{*}{ BMI } & $\begin{array}{l}\text { Less the } \\
18.5\end{array}$ & $1(3 / 2)$ & $1(3 / 2)$ & $1(3 / 2)$ & \multirow{4}{*}{0.08} \\
\hline & $18.5-25$ & $19(61 / 3)$ & $13(41 / 9)$ & $32(51 / 6)$ & \\
\hline & $25-30$ & $9(29)$ & $7(22 / 6)$ & $16(25 / 8)$ & \\
\hline & \begin{tabular}{|c|} 
Higher than \\
30
\end{tabular} & $2(6 / 5)$ & $10(32 / 3)$ & $12(19 / 4)$ & \\
\hline \multirow{3}{*}{$\begin{array}{l}\text { Birth } \\
\text { order }\end{array}$} & & $10(32 / 3)$ & $3(9 / 7)$ & 13(21) & \multirow{3}{*}{0.047} \\
\hline & Middle & $14(45)$ & $14(45 / 2)$ & $28(45 / 2)$ & \\
\hline & Last & $7(22 / 6)$ & $14(45 / 2)$ & $21(33 / 9)$ & \\
\hline \multicolumn{6}{|c|}{$\begin{array}{l}\text { Table 1. Absolute and Relative Frequency of Research Units According } \\
\text { to Demographic Variables }\end{array}$} \\
\hline
\end{tabular}

\begin{tabular}{|l|l|c|c|}
\hline \multirow{4}{*}{$\begin{array}{c}\text { Obvious } \\
\text { Anxiety }\end{array}$} & & Intervention & Control \\
\cline { 2 - 4 } & Mean \pm SD & Mean \pm SD \\
\cline { 2 - 4 } & After intervention & $52 / 74 \pm 7 / 41$ & $52 / 48 \pm 7 / 27$ \\
\cline { 2 - 4 } & P-value & $46 / 35 \pm 7 / 39$ & $51 / 81 \pm 7 / 16$ \\
\hline & $\mathrm{P}=0.001$ & $\mathrm{P}=0.13$ \\
\hline Table 2. Comparison of Mean and SD of Obvious Anxiety in the \\
Intervention and Control Group Before and After Pilates Exercise \\
\hline
\end{tabular}

\begin{tabular}{|c|c|c|c|}
\hline \multirow{4}{*}{ Hidden Anxiety } & & Intervention & Control \\
\cline { 2 - 4 } & $\begin{array}{c}\text { Before } \\
\text { intervention }\end{array}$ & $52 / 26 \pm 7 / 30$ & $52 / 77 \pm 7 / 93$ \\
\cline { 2 - 4 } & After intervention & $42 / 77 \pm 7 / 71$ & $53 / 29 \pm 7 / 42$ \\
\cline { 2 - 4 } & p-value & $\mathrm{P}=0.001$ & $\mathrm{P}=0.08$ \\
\hline
\end{tabular}

Table 3. Comparison of Mean and SD of Hidden Anxiety in the Intervention and Control Group Before and After the Pilates Exercise

Also, the mean (SD) score of hidden anxiety before and after the intervention was $52.26 \pm 7.30$ and $42.77 \pm 7.71$ in the experimental group and the difference was statistically significant $(p=0.001)$. In the control group, the mean (SD) of hidden anxiety before and after the intervention was $52.77 \pm$ 7.93 and $53.29 \pm 7.42$, respectively. Again, the difference was not statistically significant ( $\mathrm{p}=0.08$ ) (Table 3$)$.

\section{DISCUSSION}

The present study indicated that anxiety in students was significantly lower after Pilates training. Rodrigues carried out a study in Brazil titled as Pilates' method in personal autonomy, static balance and quality of life of elderly. Fifty-two elderly females participated in 60- Minutes Pilates twice weekly for eight weeks. It was concluded than the Pilates method can offer significant improvement in anxiety score in elders.(18) In a study to explore the effects of Pilates exercise on stress and anxiety in adult women, Ferreira stated that anxiety was significantly reduced after 3 month of Pilatesbased exercise.(19) The results of these studies are consistent with the present research article. The reason for anxiety improvement in the present study could be due to Pilates performed for 8 weeks. Exercises were performed in three positions including standing, sitting and lying down with deep breathing and muscular contractions which may have been effective in anxiety improvement. However, the results of a study by Segal showed that weekly 1-hour session Pilates training adult men and women over 18 for 6 months had no effect on physical condition and anxiety.(20) Age, number of weekly sessions and intensity of exercises could have resulted in these differences. In study by Segal, weekly sessions were used, and middle-aged women were recruited. Also, there was no control group in their study. These could explain the inconsistencies observed as compared to the present study. Kuo study in Australia showed that 20-Minutes Pilates-based exercises twice weekly for 10 weeks had no effects on physical heath and stress level in older adults aged over 60 years. ${ }^{(21)}$ This may be due to the limited physical ability to response to exercise in elders and the need for longer duration of exercises to reach to the intended result. The present study indicated that Pilates results in lower levels of obvious and hidden anxiety in students. Studies show that deep diaphragmatic breathing in Pilates training leads to lower levels of stress, reduced sympathetic activity and improvement in health related symptoms and anxiety.(22) Eyigor and colleagues showed that Pilates exercise sessions three times a week for a period of eight weeks resulted in the improvement of fatigue, anxiety and depression in breast cancer patients. (23)

Rashidi and colleagues (1392) carried out an experimental study to explore the effects of 8-weeks of Pilates exercise on depression in postmenopausal women. There was a significant decrease in lethargy, insomnia or hypersomnia and social isolation.(24) Considering physical and mental problems in postmenopausal women, evidence-based sport activities applicable with the least necessary equipment including Pilates training could serve as helpful tools to promote health in these individuals.

It appears that physical activity leads to reduced anxiety and mood disorders through effects on brain endorphins.(25) Physical activity is also associated with increased mental efficacy, better health and improved life related attitude.(26) Anxiety in students is reduced through physical activity and its effects on brain endorphins and reduced level of adrenal cortisol.(27) Studies have indicated that stress and anxiety are caused by low self-confidence. Since social contact is higher in group sports, self-image and self-confidence are improved. On the other hand, group sports lead to reduced stress and anxiety. (28)

\section{CONCLUSIONS}

The results indicated that Pilates could lower anxiety in students. Therefore, it is recommended as an inexpensive, appealing technique without side effects for reducing anxiety among university students.

\section{ACKNOWLEDGMENTS}

The present study was approved by student research committee. We would like to express our appreciation to all students participating in the present study. We would also like to acknowledge with much appreciation the role of research deputy of Neyshabur University of Medical Sciences for his financial support.

\section{REFERENCES}

[1] Haggerty G, Hilsenroth MJ, Vala-Stewart R. Attachment and interpersonal distress: examining the relationship 
between attachment styles and interpersonal problems in a clinical population. Clin Psychol Psychother 2009;16(1):1-9.

[2] Meamarian R. The application concepts and theories in nursing. Tehran: Tarbeat Modares University Press Publication 2009: p. 293-6. [Persian]

[3] Henker B, Whalen CK, Jamner LD, et al. Anxiety, affect and activity in teenagers: monitoring daily life with electronic diaries. J Am Acad Child Adolesc Psychiatry 2002;41(6):660-70.

[4] Scullion P. Stress and the student nurse in accident and emergency nursing. Br J Nurs 1992;1(12):27-30.

[5] Alizadeh H, Nasirifard N, Karam A. Adlerian-based encouragement training, selfefficacy and self-esteem of female adolescents studying the effectiveness. Women s studies (Sociological \& Psychological) 2010;8(4):14368. [Persian]

[6] Kingery JN, Ginsburg GS, Burstein M. Factor structure and psychometric properties of the multidimensional anxiety scale for children in an African. American Adolescent Sample. Child Psychiatry Hum Dev 2009;40(2):287-300.

[7] Physical activity. http://www.emro.who.int/ healtheducation/ physicalactivity/ background. html 24-25 February 2014. Accessed at: 30 June 2014.

[8] Goldfield GS, Adamo KB, Rutherford J, et al. The effects of aerobic exercise on psychosocial functioning of adolescents who are overweight or obese. Journal of Pediatric Psychology 2012;37(10):1136-47.

[9] Reppa GP. The effects of a new program (balance \& reform) on trait anxiety and self-esteem: a pilot study. Procedia - Soc Behav Sci 2013;84:230-2.

[10] Appell IPC, Pérez VR, De Maio NM, et al. The Pilates method to improve body balance in the elderly. Journal of Exercise in Health and Disease 2012;3(3):188-93.

[11] Altan L, Korkmaz N, Bingol U, et al. Effect of Pilates training on people with fibromyalgia syndrome: a pilot study. Archive of Physical Medicine and Rehabilitation 2009;90(12):1983-8.

[12] Deslandes AC, Moraes H, Alves H, et al. Effect of aerobic training on EEG alpha asymmetry and depressive symptoms in the elderly: a 1-year follow-up study. Braz J Med Biol Res 2010;43(6):585-92.

[13] Sjosten N, Kivela SL. The effects of physical exercise on depressive symptoms among the aged: a systematic review. Int J Geriatr Psychiatry 2006;21(5):410-8.

[14] Critchley DJ, Pierson Z, Battersby G. Effect of Pilates mat exercises and conventional exercise programmes on transversus abdominis and obliquus internus abdominis activity: pilot randomised trial. Manual Therapy 2011;16(2):183-9.

[15] Boguszewski D, Adamczyk JG, Ochal A. The role of Pilates and aquafitness exercises in sustaining the health and fitness of elderly women. Sport Science Review 2012;21(3-4):127-38.

[16] Van der Heijden MM, Van Dooren FE, Pop VJ, et al. Effects of exercise training on quality of life, symptoms of depression, symptoms of anxiety and emotional wellbeing in type 2 diabetes mellitus: a systematic review. Diabetologia 2013;56(6):1210-25.

[17] Emery K, De Serres SJ, McMillan A, et al. The effects of a Pilates training program on arm-trunk posture and movement. Clinical Biomechanics (Bristol, Avon) 2010;25(2):124-30.

[18] Rodrigues SBG, Cader AS, Torres BNV, et al. Pilates method in personal autonomy, static balance and quality of life of elderly females. Journal of Bodywork and Movement Therapies 2010;14(2):195-202.

[19] Cruz-Ferreira A, Fernandes J, Gomes D, et al. Effects of pilates-based exercise on life satisfaction, physical selfconcept and health status in adult women. Women \& Health 2011;51(3):240-55.

[20] Segal NA, Hein J, Basford JR. The effects of Pilates training on flexibility and body composition: an observational study. Archives of Physical Medicine and Rehabilitation 2004;85(12):1977-81.

[21] Kuo YL, Tully EA, Galea MP. Sagittal spinal posture after Pilates based exercise in healthy older adults. Spine 2009;34(10):1046-51.

[22] Marques NR, Morcelli MH, Hallal CZ, et al. EMG activity of trunk stabilizer muscles during Centering Principle of Pilates Method. Journal of Bodywork and Movement Therapies 2013;17(2):185-91.

[23] Eyigor S, Karapolat H, Yesil H, et al. Effects of Pilates on functional capacity, flexibility, fatigue, depression and quality of life in female breast cancer patients:a randomized controlled study. European Journal of Physical and Rehabilitation Medicine 2010;46(4):4817.

[24] Rashidi Z, Daneshfar A, Shojaei M, et al. Scrutiny effects of eight-weeks Pilates exercise on women's postmenopausal depressive symptoms. Journal of Isfahan Medical School 2013;31(231):408-15.

[25] Nikbakht M, Ebadi GH. The comparison of two training methods of walking and running on the premenstrual syndrome (PMS) in high school girls of Ahwaz. Research on Sport Science 2007;4(14):54-69.

[26] Mishell DR Jr. Premenstrual disorders: epidemiology and disease burden. Am J Manag Care 2005;11(Suppl 16):S473-9.

[27] Rutjes AW, Di Nisio M. 24 weeks of Pilates-aerobic and educative training to improve body fat mass in elderly Serbian women. Clinical Interventions in Aging 2014;9:741-2.

[28] Marinda F, Magda G, Ina S, et al. Effects of a mat Pilates program on cardiometabolic parameters in elderly women. Pakistan Journal of Medical Sciences 2013;29(2):500-4. 